\title{
The Feasibility of Sound Waves to Treat Microbial Disease
}

\author{
Xenia Zhao \\ Hamilton High School, 3700 S. Arizona Ave. Chandler, AZ, 85248, U.S.A.; loutzenheiser.sara@cusd80.com
}

ABSTRACT: As antibiotics become less effective against superbugs, the need for alternative treatment has increased. The purpose of this experiment is to better understand the relationship between audible sound and bacterial growth in hopes of a potential alternative to standard disease prevention practices. One control and three experimental groups, inoculated with Escherichia coli, were exposed to different frequencies of sound waves in the audible sound spectrum. Colony diameter $(\mathrm{mm})$ was measured using ImageJ software. There was an inverse relationship between sound wave frequency $(\mathrm{Hz})$ and colony diameter $(\mathrm{mm})$; as frequency increases, colony diameter decreases. The control group $(0 \mathrm{~Hz})$ exhibited average colony diameter $2.733 \mathrm{~mm}$, experimental group $432 \mathrm{~Hz}$ had average colony diameter $1.987 \mathrm{~mm}$, experimental group $802 \mathrm{~Hz}$ had average colony diameter $1.696 \mathrm{~mm}$, and experimental group $4000 \mathrm{~Hz}$ had average colony diameter $1.442 \mathrm{~mm}$. This implies that higher frequency sound waves have an adverse impact on bacterial growth, thus suggesting its usability in the medical field as a way to fight microbial disease. However, it cannot eradicate existing bacteria. Sound therapy cannot fully treat bacterial infection, but it is associated with the ceasing of proliferation and the prevention of infection.

KEYWORDS: Microbiology; Sound; Frequency; Energy; Disease; Medicine; Bacteria.

\section{Introduction}

The sound that is registered in human ears is energy-the energy produced when molecules vibrates. When an object vibrates, it utilizes kinetic energy; as the object moves, its kinetic energy is transferred to the surrounding molecules, and the energy successively travels throughout the medium. ${ }^{1}$ The sound wave spreads out in a process called diffraction, and as sound waves move through the air, they create compressions and rarefactions, respectively pushing and pulling the air. ${ }^{1}$ The amplitude of a sound wave, the maximum displacement of the average molecule as it oscillates back and forth, determines its perceived loudness. ${ }^{1}$ The frequency of the sound wave, how fast the average molecule completes a cycle, determines the perceived pitch. In classical physics, the energy contained in a sound wave is determined by the change in air pressure-amplitude-measured in decibels. ${ }^{1}$ However, energy in modern physics can be quantized. The vibrational energy in sound waves can be exchanged through something known as phonons. ${ }^{2}$ The equation to calculate the energy of a phonon is given by the following:

$E=h v$, where $h=$ Planck's constant $\left(6.62607004 \cdot 10^{-34} \mathrm{~J} \mathrm{~s}\right), v=$ phonon frequency

\section{DV: Bacterial Growth}

Once pathogenic bacteria enter their host, they multiply rapidly, crowd out the host tissue, and create toxins. ${ }^{3}$ Limiting bacterial reproduction prevents the spread of disease, giving the body time to eliminate the pathogens. Bacteria are simple prokaryotes with circular DNA.3 Electrons flow through the bacteria's DNA loop, producing energy when those electrons change energy levels. ${ }^{4}$ Therefore, because bacteria produce energy, they respond differently to various levels of energy, as intuitively expected.

\section{Literature Review}

A previous study demonstrated the ability of sound waves (at frequency $400,000 \mathrm{~Hz}$ ) to break up luminous bacteria. ${ }^{5}$ More recently, a study showed that audible sound had a positive effect on bacterial growth-the exposure of colonies to sound waves increased bacterial growth rate. ${ }^{6}$ Another study performed more extensive research and found that bacterial growth increased when exposed to frequencies below $1 \mathrm{KHz}$ and decreased above $1 \mathrm{KHz} .{ }^{7}$ These results are inconsistent with Harvey and Loomis 1929, but are more recent. There is little other research to compare these results to, thus leading to a gap in the research, which this experiment attempts to fill.

\section{Experimental Design}

The purpose of this experiment is to test a few frequencies in the audible hearing range $(20 \mathrm{~Hz}$ to $20 \mathrm{KHz})$ in order to better understand the interaction between sound waves and bacteria. This experiment also focused on colony size rather than growth rate since colony size is more indicative of how widespread a pathogen is in the body. If we can understand the relationship between the two variables, we can apply this novel method of bacterial treatment as a safe, alternative form to traditional antibiotic treatments. The research question is: How does sound wave frequency affect bacterial growth? The hypothesis presented is: If sound waves are applied to plates of E. coli and growth is allowed to occur, then the $4000 \mathrm{~Hz}$ sound waves will decrease bacterial growth the most, and the least effective sound wave will be the control group. This is because $\mathrm{E}$. 
coli should fail under high amounts of energy, while thriving with no interference.

\section{Results and Discussion}

Table 1. Sound frequencies used for experiment were $0 \mathrm{~Hz}, 432 \mathrm{~Hz}, 802 \mathrm{~Hz}$, and $4000 \mathrm{~Hz}$.

\begin{tabular}{|l|l|}
\hline $\begin{array}{l}\text { Sound wave } \\
\text { frequency }(\mathrm{Hz})\end{array}$ & $\begin{array}{l}\text { Energy of one } \\
\text { phonon }(\mathrm{J})\end{array}$ \\
\hline 0 & 0 \\
\hline 432 & $2.86246226 \mathrm{E}-31$ \\
\hline 802 & $5.31410817 \mathrm{E}-31$ \\
\hline 4000 & $2.65042802 \mathrm{E}-30$ \\
\hline
\end{tabular}

As sound wave frequency $(\mathrm{Hz})$ increases, colony diameter $(\mathrm{mm})$ decreases. A one-way ANOVA test shows that the F statistic (7.24) is greater than the critical statistic (2.52), meaning that the difference is statistically significant. There is an inverse relationship between the variables. The control group $(0 \mathrm{~Hz})$ exhibited average colony diameter $2.733 \mathrm{~mm}$, experimental group $432 \mathrm{~Hz}$ had average colony diameter $1.987 \mathrm{~mm}$, experimental group $802 \mathrm{~Hz}$ had average colony diameter $1.696 \mathrm{~mm}$, and experimental group $4000 \mathrm{~Hz}$ had average colony diameter $1.442 \mathrm{~mm}$. See Table 2 and Figure 1 for all collected data and graphical trends, respectively.

The hypothesis was partially supported, because instead of a direct functional dependence as predicted, there was an inverse functional dependence between the two variables.

Table 2. complete data set collected. T1.1 and T1.2 represent two different colonies from the same plate. On average, as sound wave frequency $(\mathrm{Hz})$ increases, colony diameter $(\mathrm{mm})$ decreases.

\begin{tabular}{|c|rrrr|}
\hline \multirow{2}{*}{$\begin{array}{c}\text { Colony } \\
\text { Diameter }(\mathrm{mm})\end{array}$} & \multicolumn{4}{|c|}{ Sound Wave Frequency $(\mathrm{Hz})$} \\
\cline { 2 - 5 } & 0 & 432 & 802 & 4000 \\
\hline $\mathrm{T} 1.1$ & 2.198 & 2.140 & 2.189 & 1.634 \\
$\mathrm{~T} 1.2$ & 2.185 & 1.736 & 1.754 & 1.993 \\
$\mathrm{~T} 1.3$ & 2.273 & 2.315 & 1.536 & 1.185 \\
$\mathrm{~T} 2.1$ & 2.650 & 1.677 & 1.988 & 1.237 \\
$\mathrm{~T} 2.2$ & 2.076 & 2.144 & 1.610 & 1.485 \\
$\mathrm{~T} 2.3$ & 2.031 & 1.795 & 1.969 & 1.384 \\
$\mathrm{~T} 3.1$ & 3.733 & 2.291 & 1.590 & 1.447 \\
$\mathrm{~T} 3.2$ & 5.395 & 1.676 & 1.490 & 1.689 \\
$\mathrm{~T} 3.3$ & 2.055 & 2.109 & 1.137 & 0.920 \\
\hline Average & 2.733 & 1.987 & 1.696 & 1.442 \\
\hline
\end{tabular}

Like all experiments involving bacteria, there were many possible errors. When plating the petri dishes, the lid was opened to streak the bacteria, and some specimen in the air could have landed on the nutrient agar, thereby reducing surface area available for the $E$. coli to grow. Furthermore, the containers in which the sound was applied was not completely soundproof; thus, some noise interference could have entered the system and skewed the results. However, these effects were minimized as much as possible. Should the experiment be repeated, the researcher should include more intermediate levels to better determine trends in the graph. They should also use more sound-proof containers to obtain more accurate results.

One concern is that the bacteria were allowed to grow for 17 hours before treated with sound, and because the colonies should not have diminished in size, the ones treated with low- er/no frequency sound must have grown to account for the different in colony size. This seems unlikely but is not entire-

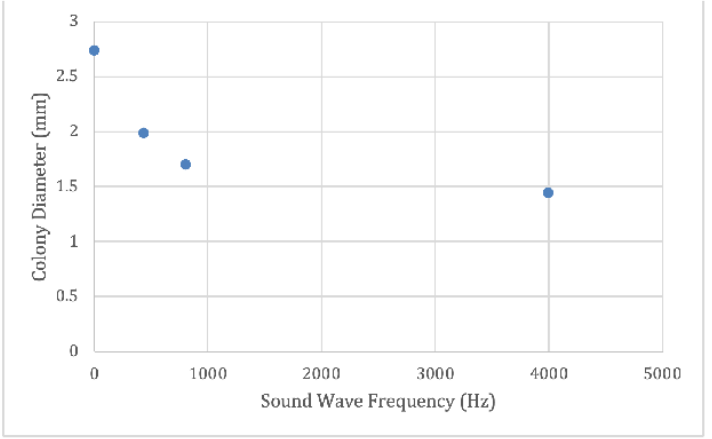

Figure 1. Graphical trends of data collected. Colony diameter $(\mathrm{mm})$ is inversely correlated with an increase in sound frequency $(\mathrm{Hz})$.

ly impossible because bacteria on a plate grow exponentially, and the E. coli were already substantial pre-sound treatment. To better isolate the independent variable and confirm results, if replicated, testing of the dependent variable should be performed twice-once before sound treatment, and once afterwards.

It is important to note that this experiment was only performed with $E$. coli bacteria and is narrow in scope. Further study could investigate other types of bacteria and even virus. Future research could also study the effect of sound frequency on healthy human cells. This is immensely important, as it would not be safe to use sound therapy to kill bacteria if it killed human cells as well. Another topic of research could be the effect of sound treatment on antibiotic resistance. Since sound treatment has been proven in this experiment to change bacterial formation, it is possible that behavior has changed, possibly weakening their ability to resist traditional antibiotics.

\section{Conclusion}

Higher sound wave frequencies have negative effects on bacterial growth; this suggests its potential utility in the medical field as a way to prevent microbial disease. However, colony size seems to stop short of the $\mathrm{x}$-axis, approaching an asymptote. Thus, audible sound may not be able to completely eradicate all bacteria. Sound therapy cannot fully treat bacterial infection. However, it can stop proliferation and prevent bacterial infection to an extent.

\section{- Methods}

First, we prepared twelve $90 \mathrm{~mm}$ petri dishes with nutrient agar, and transferred the E. coli from the culture (Home Science Tools (Billings, MT) to each petri dish using a sterile inoculating needle and the streak plate method with four quadrants. Then, the plates were secured, labeled, and put into an incubator at $37^{\circ} \mathrm{C}$ for 17 hours (see Figure 2). Plates contained $(5 \mathrm{~g})$ dehydrated nutrient agar or $(200 \mathrm{ml})$ prepared nutrient agar. 


\section{Experiment}

We took the 3 plates labeled with level 1 out of the incubator and transferred them to a sound-proof container at $21^{\circ} \mathrm{C}$ and

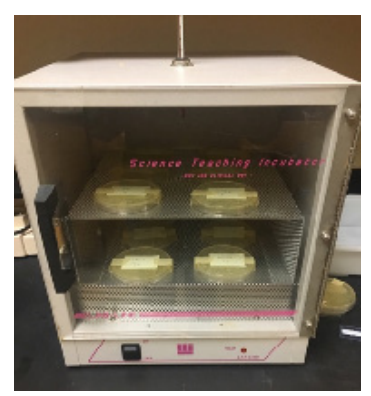

Figure 2. Petri dishes in incubator.

applied $0 \mathrm{~Hz}$ sound at $50 \mathrm{~dB}$ for 1 hour. This was repeated for the other 3 levels, changing the sound frequency as outlined in Table 2. When all plates had finished experimentation, we poured household bleach (10\%) over all petri dishes before disposing of them properly. All safety precautions, including wearing gloves and washing hands, were observed carefully.

Data Analysis:

We used Image software $[9,10]$ to determine colony diameter size. (see Figure 3)

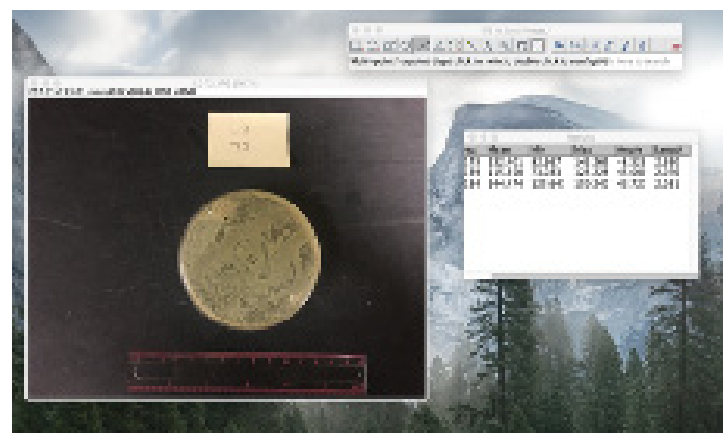

Figure 3. Collecting data with ImageJ software.

\section{Acknowledgements}

A special thank you to Mrs. Sara Loutzenheiser, who supervised this research project and allowed usage of her lab space. No funding received.

\section{References}

1. Woodford, C. (2018). Sound. Explain That Stuff. www.explainthatstuff.com/sound.html..

2. Paschotta, R. Phonons. Encyclopedia of Laser Physics and

Technology, https://www.rp-photonics.com/phonons.html

3. Drexler, M. (2010). What You Need to Know About Infectious Disease. National Academies Press, https://www.ncbi.nlm.nih.gov/books/NBK209710/

4. Widom, A., Swain, J., Srivastava Y. N., \& Sivasubramanian S. (2011). Electromagnetic Signals from Bacterial DNA. Cornell University. arXiv: 1104.3113

5. Harvey, E. N. and Loomis, A. L. (1929). The Destruction of Luminous Bacteria by High Frequency Sound Waves. Journal of Bacteriology, 17(5), 373-376. ncbi.nlm.nih.gov/pmc/articles/PMC375061/

6. Gu, S., Zhang, Y., \&Wu, Y. (2016). Effects of sound exposure on the growth and intracellular macromolecular synthesis of E. coli k-12. Peer J, 4. doi:10.7717/peerj.1920

7. Banerjee, S., Goswami, A., Datta, A., Pyne, A., Nikhat, A., \& Ghosh, B. (2018). Effect of different sound frequencies on the growth and antibiotic susceptibility of Escherichia coli. International Journal of Current Microbiology and Applied Sciences, 7(3), 1931-1939. https://doi.org/10.20546/ijcmas.2018.703.229

8. Safety Guidelines. (2006). Microbiology Online, Microbiology Society. https://microbiologyonline.org/teachers/safety-information/ safety-guidelines

9. Schindelin, J., Arganda-Carreras, I., Frise, E., Kaynig, V., Longair, M., Pietzsche, T., Preibisch, S., Rueden, C., Saalfeld, S., Schmid, B., Tineyez, J., White, D. J., Hartenstein, V., Eliceiri, K., Tomancak, P., \& Cardona, A. (2012), Fiji: an open-source platform for biological-image analysis. Nature methods 9(7): 676-682, PMID 22743772, doi:10.1038/nmeth.2019.

10.Schindelin, J.; Rueden, C. T. \& Hiner, M. C. et al. (2015), The ImageJ ecosystem: An open platform for biomedical image analysis. Molecular Reproduction and Development, PMID 26153368.

\section{Authors}

Xenia Zhao is a student at Hamilton High School. Her favorite subject is physics. In her free time, she likes hiking, painting, and dancing to music. 